\title{
The contact phase of coagulation in the presence of heparin
}

\author{
A. L. BLOOM
}

From the Institute of Pathology, Royal Infirmary, Cardiff

SYNOPSIS The effect of heparin on the contact phase of coagulation has been investigated by a technique utilizing a solution of toluidine blue in calcium chloride. Heparin in a concentration of os 7 units/ml. of plasma does not inhibit contact activation by glass. It is suggested that heparin does not prevent the activation of factor XII (Hageman factor) by glass or the subsequent formation of active factor XI (plasma thromboplastin antecedent).

The antithrombin effect of heparin has been known for many years. Biggs, Douglas, and Macfarlane (1953) have shown that heparin also inhibits the formation of plasma thromboplastin, and O'Brien (1958 and 1960) considers that this is due to its effect on factor IX (Christmas factor). The earlier stages of the coagulation mechanism in vitro involve factor XI and factor XII. According to Hardisty and Margolis (1959) and Soulier and Prou-Wartelle (1960), contact of plasma with glass or other forms of silica results in the adsorption and activation of factor XII. Activated factor XII then reacts with factor XI which in turn is activated and in the presence of calcium initiates further stages of thromboplastin generation. The reactions leading to the formation of active factor XI are referred to as the contact phase of coagulation. Contact with glass normally plays no part in the establishment of haemostasis in vivo and presumably these early stages of coagulation are effected by some other means, possibly associated with tissue fluids (Biggs and Nossel, 1961). When an extracorporeal circulation, such as the heart-lung machine or artificial kidney, is used, however, blood is brought into contact with 'foreign' surfaces and recirculated in the patient. The extracorporeal circuit, in fact, temporarily becomes part of the patient's circulation. Heparin has been widely used in high concentration to prevent coagulation occurring during these procedures. A knowledge of the effect of heparin on all stages of the coagulation mechanism, including the contact phase, may therefore be of considerable practical importance. The investigations reported here show that a high concentration of heparin in citrated plasma does not inhibit contact activation of the coagulation mechanism.

Received for publication 5 June 1962.

\section{MATERIALS}

TOLUIDINE BLUE-CALCIUM CHLORIDE REAGENT This reagent was prepared by dissolving powdered toluidine blue in $\mathrm{M} / 20$ calcium chloride to a concentration of $\vec{\varphi}$ $100 \mathrm{mg}$. \%. The solution was filtered immediately before use.

HEPARIN A solution of Pularin (Evans), 5,000 units per $\mathrm{ml}$., was diluted appropriately in normal saline.

GLASSWARE Unless otherwise stated all glass apparatus was siliconed on both inner and outer surfaces.

INTACT NORMAL PLASMA Blood was taken without the use of a venous tourniquet into $3.8 \% \mathrm{w} / \mathrm{v}$ trisodium citrate in the proportion of 9 volumes of blood to 1 volume of citrate. It was centrifuged at 3,000 r.p.m. for 20 minutes? and the supernatant was recentrifuged for a further 0 20 minutes to eliminate platelets as far as possible.

CONTACTED HEPARINIZED PLASMA Intact normal plasma, $0.9 \mathrm{ml}$., was transferred to a tube and to it was added 을 $0.1 \mathrm{ml}$. of a solution of heparin at a concentration of 70 units $/ \mathrm{ml}$. The final concentration was therefore 7 unitso of heparin per millilitre of slightly diluted plasma. Twelve unsiliconed glass beads of $2 \mathrm{~mm}$. diameter were placed $\mathrm{N}$ in the tube which was stoppered with a polythene-covered rubber bung and rotated on a Matburn mixer at 28 r.p.m. for 15 minutes. The concentration of heparin used is $\omega$ approximately that which is commonly attained in extra-ত corporeal circuits. The small number of relatively largeo glass beads was used to produce minimal contact $\frac{?}{\mathscr{D}}$ activation.

CONTACTED NORMAL PLASMA This was prepared in aO similar manner to contacted heparinized plasma, $0.1 \mathrm{ml}$ of normal saline being substituted for the heparin.

The tubes containing the freshly prepared contacted? plasma were transferred to a bath of melting ice and 
tested immediately. Plasma from the same donor was used for each experiment.

CEPHALIN A chloroform extract of brain was used as a substitute for platelet extract. This was prepared by the method of Bell and Alton (Biggs and Macfarlane, 1957) and was used at the optimum concentration of $1: 100$ in normal saline.

\section{METHODS}

TEST FOR CONTACT ACTIVATION Margolis' indirect method (Margolis, 1957) was used modified to allow for testing in the presence of heparin and using brain cephalin instead of platelet extract. Rows of tubes were placed in a bath of melting ice. In them a series of five threefold dilutions of contacted normal or heparinized plasma were made in intact normal plasma which had been diluted with onetenth volume of saline. The contacted plasma samples also contained this proportion of saline or heparin solution. The range of concentrations of contacted in intact plasma was then 1 in 3 to 1 in 243 . To $0.2 \mathrm{ml}$. of each dilution was added $0.05 \mathrm{ml}$. of cephalin. A row of tubes was transferred to a water bath at $37^{\circ} \mathrm{C}$. and after three minutes $0.1 \mathrm{ml}$. of the toluidine blue-calcium chloride reagent was added to each tube in turn. The recalcification times were determined using a bank of stop watches. Delay in testing and prolonged incubation of the mixtures at $37^{\circ} \mathrm{C}$. were thus avoided. In some experiments recalcification was performed with $\mathrm{M} / 20$ calcium chloride alone. The beads used to prepare contacted plasma were the only unsiliconed glass to come into contact with the plasma at any stage in this test.

Preliminary experiments were performed to determine if toluidine blue is a suitable heparin antagonist for this study. Details are given below.

\section{RESULTS}

EFFECT OF TOLUIDINE BLUE IN NEUTRALIZING HEPARIN O'Brien (1958) stated that toluidine blue failed to correct the abnormal thromboplastin generation produced by heparin. The effect of toluidine blue in correcting the calcium-cephalin clotting time of heparinized plasma was therefore investigated. Contacted normal plasma was prepared to contain concentrations of heparin similar to those obtained in the indirect test described above, i.e. $2 \cdot 3$ units to 0.029 unit per $\mathrm{ml}$. To $0.2 \mathrm{ml}$. of each sample in siliconed tubes was added $0.05 \mathrm{ml}$. of cephalin. The tubes were transferred to a water bath at $37^{\circ} \mathrm{C}$. and after three minutes $0.1 \mathrm{ml}$. of the toluidine bluecalcium chloride reagent was added and the clotting times determined. The experiment was repeated recalcifying with $\mathrm{M} / 20$ calcium chloride alone. Table I shows that the addition of toluidine blue with the calcium chloride satisfactorily neutralizes heparin. Toluidine blue prolongs the calcium-cephalin clotting time, but this effect is independent of the con-
TABLE I

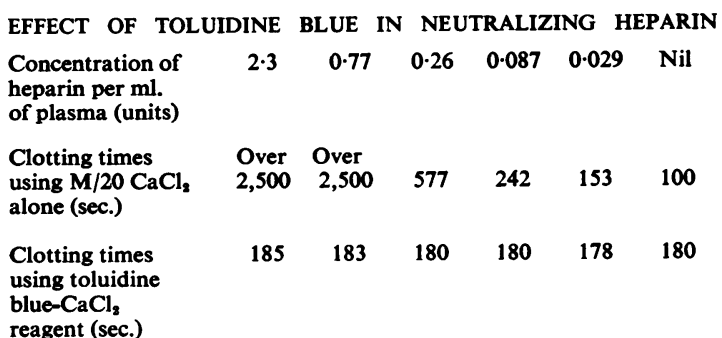

centration of heparin present provided the latter is completely neutralized. Protamine sulphate and Polybrene (hexadimethrine bromide) are other substances which neutralize heparin. In excess they also prolong the calcium clotting time but this effect varies with the concentration of heparin. In the indirect test for contact activation used in this investigation the concentration of heparin is varied by dilution. For this reason toluidine blue has been used as the antiheparin agent of choice. Incubation of plasma with toluidine blue causes a further prolongation of the calcium-cephalin clotting time and for this reason the combined toluidine blue-calcium chloride reagent was used.

EFFECT OF TOLUIDINE BLUE IN DETECTING CONTACT ACTIVATION Margolis' indirect test was performed as described on contacted normal plasma. The effect of recalcification with toluidine blue-calcium chloride reagent was compared with that of recalcification with $\mathrm{M} / 20$ calcium chloride alone. Table II shows the results. Although the presence of toluidine blue prolongs the clotting times, the effect of the contacted plasma on the intact plasma is easily detectable.

THE EFFECT OF HEPARIN ON CONTACT ACTIVATION The indirect test was performed on contacted normal

\section{TABLE II}

DETECTION OF CONTACT ACTIVATION OF NORMAL PLASMA USING TOLUIDINE BLUE-CALCIUM CHLORIDE REAGENT

\begin{tabular}{|c|c|c|c|c|c|c|}
\hline $\begin{array}{l}\text { Dilution of contacted } \\
\text { plasma in intact } \\
\text { plasma }\end{array}$ & $1: 3$ & $1: 9$ & $1: 27$ & $1: 81$ & $1: 243$ & $1: 00$ \\
\hline $\begin{array}{l}\text { Clotting times on } \\
\text { addition of } \mathrm{M} / 20 \\
\mathrm{CaCl}_{2} \text { (sec.) }\end{array}$ & 142 & 180 & 203 & 248 & 271 & 304 \\
\hline $\begin{array}{l}\text { Clotting times on } \\
\text { addition of toluidine } \\
\text { blue-CaCl } \\
\text { reagent (sec.) }\end{array}$ & 258 & 284 & 363 & 386 & 517 & 710 \\
\hline
\end{tabular}

Cephalin, $0.05 \mathrm{ml}$., was added to $0.2 \mathrm{ml}$. of each dilution of contacted plasma.

The clotting times were determined after the addition of $0.1 \mathrm{ml}$. of $\mathrm{M} / 20 \mathrm{CaCl}_{2}$ or toluidine blue- $\mathrm{CaCl}_{2}$ reagent. 
plasma and contacted heparinized plasma using the toluidine blue-calcium chloride reagent. Table III gives the results of such an experiment. The clotting times with heparinized plasma are very similar to those with normal plasma and clearly show that heparin has no inhibitory effect even on the minimal contact activation produced by a small number of glass beads.

\section{TA BLE III}

EFFECT OF HEPARIN ON CONTACT ACTIVATION OF NORMAL PLASMA

$\begin{array}{llllll}\begin{array}{l}\text { Dilution of contacted plasma } \\ \text { in intact normal plasma }\end{array} & 1: 3 & 1: 9 & 1: 27 & 1: 81 & 1: 243 \\ \begin{array}{l}\text { Clotting times (sec.) with } \\ \text { contacted normal plasma }\end{array} & 238 & 280 & 375 & 480 & 575 \\ \begin{array}{l}\text { Clotting times (sec.) with } \\ \text { contacted heparinized plasma }\end{array} & 245 & 298 & 384 & 480 & 595 \\ \end{array}$

Cephalin, $0.05 \mathrm{ml}$., was added to $0.2 \mathrm{ml}$. of each dilution of contacted plasma. The clotting times were determined after the addition of $0.1 \mathrm{ml}$. of toluidine blue- $\mathrm{CaCl}_{2}$ reagent.

\section{DISCUSSION}

According to Hardisty and Margolis (1959) contact of plasma with glass results in the adsorption and activation of factor XII which in turn adsorbs and activates factor XI. Activated factor XI then returns into solution and initiates further stages in the formation of thromboplastin. Activated factor XI in solution is presumably responsible for the activity in the contacted citrated platelet-poor plasma used in Margolis' indirect test. Heparin does not prevent the formation of this soluble active agent and therefore if the theory of Hardisty and Margolis is correct heparin does not prevent the formation of activated factor XI or the reactions which precede it.

Little information has previously been available on the effect of heparin on contact activation. Conley, Hartmann, and Lalley (1950) showed that contact with glass shortened the clotting time of native platelet-poor plasma containing heparin to a concentration of $0.075 \mathrm{unit} / \mathrm{ml}$. and that this effect was proportional to the area of glass to which such plasma was exposed. They could not, however, demonstrate this effect with higher concentrations of heparin because the plasma then became incoagulable. The results presented here support the findings of these workers. O'Brien (1960) stated that heparin does not affect the coagulant activity of factor XII although his experiments were not designed to detect its effect on the contact phase of coagulation and the concentration of heparin used was lower than that used in the present investigation. Gormsen (1961), using celite, found that the heparin resistance of contacted plasma is greater than that of intact plasma but did not test the effect of heparin on celite activation. The effect of heparin on the interaction of activated factor XI with calcium and other thromboplastic factors has not been tested in the experiments described here, since at this stage toluidine blue was added to the system.

Ollendorff, Storm, Rygg, and Arnfred (1961) were able to demonstrate activation of the 'thromboplastic system' when heparinized blood was circulated through a heart-lung machine used as a closed circuit or with a patient. They suggest that this might be a foreign surface reaction involving factor XII and factor XI, but admit that their technique did not demonstrate the stages or factors involved in thromboplastin generation which were effected. The results presented in this paper suggest that activation of factor XII and factor XI during extracorporeal circulation of blood will not be prevented by heparin if a suitable surface is present in the circuit.

\section{REFERENCES}

Biggs, R., Douglas, A. S., and Macfarlane, R. G. (1953). J. Physiol. (Lond.), 122, 554.

- and Macfarlane, R. G. (1957). Human Blood Coagulation and its Disorders, 2nd ed., p. 396. Blackwell, Oxford.

and Nossel, H. L. (1961). Thrombos. Diathes. haemorrh. (Stuttg.), $6,1$.

O'Brien, J. R. (1958). Nature (Lond.), 181, 1801.

, (1960). J. clin. Path., 13, 93.

Conley, C. L., Hartmann, R. C., and Lalley, J. S. (1950). J. clin. Invest., 29, 470 ,

Gormsen, J. (1961). Thrombos. Diathes, haemorrh. (Stuttg.), 6, 144. Hardisty, R. M., and Margolis, J. (1959). Brit. J. Haemat., 5, 203.

Margolis, J. (1957). J. Physiol. (Lond.), 137, 95.

Ollendorff, P., Storm, O., Rygg, I., and Arnfred, E. (1961). Acta G chir. scand., 122, 217.

Soulier, J.-P., and Prou-Wartelle, O. (1960). Brit. J. Haemat., 6, 88. 